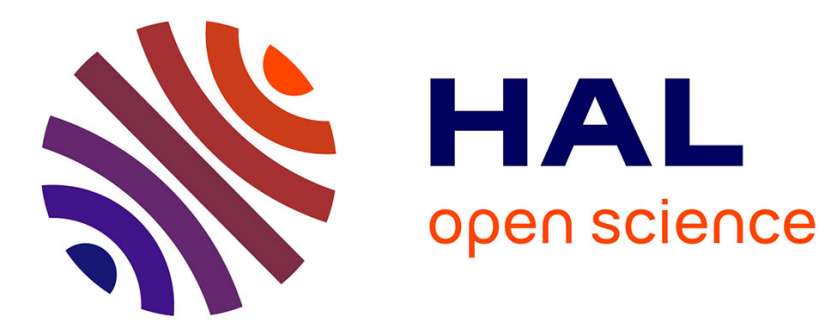

\title{
Airflow driven fluid--structure interaction subjected to aqueous-based liquid spraying
}

\author{
A. Bouvet, X. Pelorson, Annemie van Hirtum
}

\section{To cite this version:}

A. Bouvet, X. Pelorson, Annemie van Hirtum. Airflow driven fluid-structure interaction subjected to aqueous-based liquid spraying. Physics of Fluids, 2020, 32 (8), pp.081901. 10.1063/5.0015587 . hal-02920392

\section{HAL Id: hal-02920392 \\ https://hal.science/hal-02920392}

Submitted on 24 Aug 2020

HAL is a multi-disciplinary open access archive for the deposit and dissemination of scientific research documents, whether they are published or not. The documents may come from teaching and research institutions in France or abroad, or from public or private research centers.
L'archive ouverte pluridisciplinaire HAL, est destinée au dépôt et à la diffusion de documents scientifiques de niveau recherche, publiés ou non, émanant des établissements d'enseignement et de recherche français ou étrangers, des laboratoires publics ou privés. 


\section{Airflow driven fluid-structure interaction subjected to aqueous-based liquid spraying}

Cite as: Phys. Fluids 32, 081901 (2020); https://doi.org/10.1063/5.0015587

Submitted: 29 May 2020 . Accepted: 15 July 2020 . Published Online: 03 August 2020

A. Bouvet, X. Pelorson, and A. Van Hirtum (D)
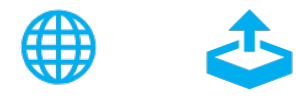

\section{ARTICLES YOU MAY BE INTERESTED IN}

Passive and active control of turbulent flows

Physics of Fluids 32, 080401 (2020); https://doi.org/10.1063/5.0022548

Pulsed-jet propulsion via shape deformation of an axisymmetric swimmer

Physics of Fluids 32, 081902 (2020); https://doi.org/10.1063/5.0015498

Invisibility concentrator for water waves

Physics of Fluids 32, 081701 (2020); https://doi.org/10.1063/5.0019129

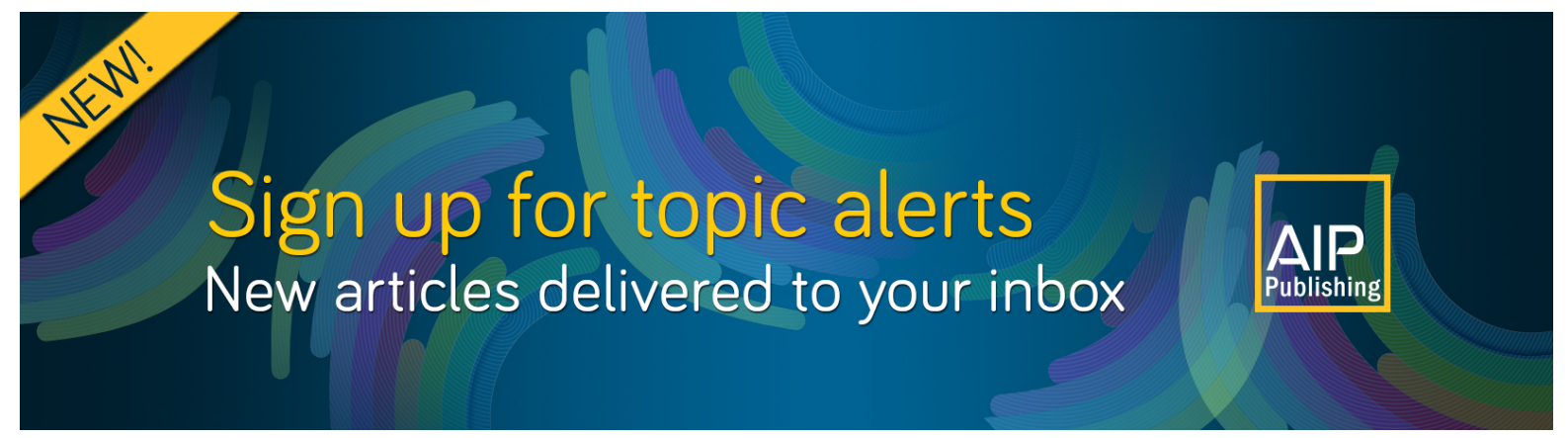




\title{
Airflow driven fluid-structure interaction subjected to aqueous-based liquid spraying
}

\author{
Cite as: Phys. Fluids 32, 081901 (2020); doi: 10.1063/5.0015587 \\ Submitted: 29 May $2020 \cdot$ Accepted: 15 July $2020 \cdot$ \\ Published Online: 3 August 2020
}

A. Bouvet, ${ }^{\text {a) }}$ X. Pelorson, ${ }^{\text {b) }}$ and A. Van Hirtum ${ }^{c}$

AFFILIATIONS

LEGI, UMR CNRS 5519, Grenoble Alpes University, Grenoble, France

a)Electronic mail: anne.bouvet@univ-grenoble-alpes.fr

b) Electronic mail: xavier.pelorson@univ-grenoble-alpes.fr

${ }^{c}$ Author to whom correspondence should be addressed: annemie.vanhirtum@univ-grenoble-alpes.fr

\begin{abstract}
Artificial saliva sprays are commonly used to remedy vocal folds surface hydration. Vocal folds surface hydration and its effect on their autooscillation are studied experimentally using artificial vocal folds. The airflow is used to excite the vocal folds into auto-oscillation after which the vocal folds surface is sprayed with a liquid. The validity of the findings described in a previous study [A. Bouvet, X. Pelorson, and A. Van Hirtum, "Influence of water spraying on an oscillating channel," J. Fluids Struct. 93, 102840 (2020)] concerning the effect of water spraying is further investigated. First, artificial saliva sprays (up to $5 \mathrm{ml}$ ) are sprayed instead of water. It is shown that this allows us to address the effect of increased dynamic viscosity (up to 8 times compared to water) as other artificial saliva properties affecting air-liquid mixing and surface wettability remain similar to water. Second, the Reynolds number in the dry stage is systematically increased (with $60 \%$ ) for constant spraying volume $\geq 3 \mathrm{ml}$. Regardless of the sprayed liquid and Reynolds number, oscillation cycles are characterized by an increase in mean upstream pressure, cycle-to-cycle variability, and a decrease in oscillation frequency due period doubling. Increasing the dynamic viscosity tends to reduce the magnitude of these tendencies for spraying volumes smaller than $3 \mathrm{ml}$, indicating that viscous liquid-gas mixing affects the flow regime. Systematic Reynolds number variation shows that liquid spraying increases the oscillation onset threshold pressure and that the magnitude of general tendencies is reduced. The assessed conditions and features are pertinent to human voice production after hydration with an artificial saliva spray burst.
\end{abstract}

Published under license by AIP Publishing. https://doi.org/10.1063/5.0015587

\section{INTRODUCTION}

Voiced speech sound production occurs due to an airflowdriven fluid-structure (FS) instability between the airflow coming from the lungs and the surrounding deformable vocal folds (VFs) tissues. The surface of human VFs is hydrated with a liquid layer, ${ }^{1,2}$ and it is established that good surface hydration diminishes phonotraumatic lesions ${ }^{2,3}$ and benefits voice quality. ${ }^{4-8}$ Hydration affects the oscillation frequency and its spectral features as well as the vocal effort, determined by the oscillation amplitude and needed upstream lung pressure. In addition, the cycleto-cycle perturbations of the oscillation period and the amplitude, expressed by the jitter and shimmer, respectively, are clinical voice quality parameters sensible to hydration. Consequently, the use of artificial saliva sprays to remedy VF surface hydration is widespread. $^{9-11}$
Whereas the physical principles underlying the FS instability are well studied, ${ }^{12-17}$ the potential role of VF's surface hydration in the FS interaction is only marginally investigated. Recently, the effect of surface hydration following water spraying on a deformable auto-oscillating channel portion inserted in a rigid tube was studied experimentally. ${ }^{18,19}$ The setup consists of a mechanical deformable VF replica, concretely a pressurized latex tube (PLT) VF replica, mounted between two rigid uniform tubes representing the trachea (inferior end) and oral tract (superior end), as illustrated in Fig. 1. Auto-oscillation near the oscillation onset pressure threshold, i.e., the minimum upstream pressure required to sustain oscillation, was considered, and perturbation measures expressing voice quality in clinical studies ${ }^{5,7,8}$ were quantified on the oscillating upstream pressure gathered before and after water spraying. ${ }^{18}$ The volume of sprayed water was systematically varied between $1 \mathrm{ml}$ up to $5 \mathrm{ml}$ so that the applied volume range is pertinent to spray bursts, nebulizing 


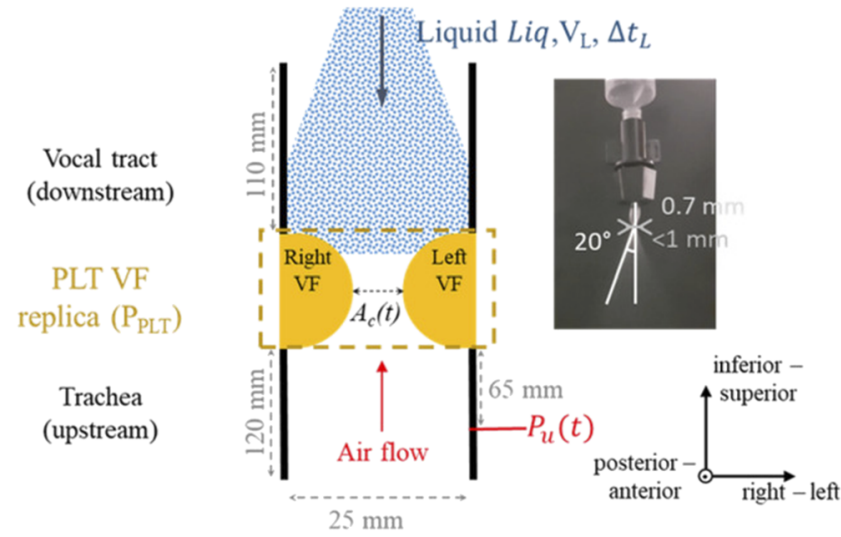

FIG. 1. Overview of the experimental setup: uniform rigid trachea pipe (upstream), uniform rigid vocal tract pipe (downstream), and in-between deformable mechanical PLT VF replica [elasticity condition $P_{P L T}$ and glottal constriction area $A_{c}(t)$ ], liquid spray characteristics (label Liq, volume $V_{L}$, and spray duration $\Delta t_{L}$ ), and driving airflow [upstream pressure $P_{u}(t)$ ]. The sprayed liquid jet issuing from a syringe equipped with a spray nozzle is shown.

up to $4 \mathrm{ml}$ each, during hydration remediation with artificial saliva sprays. $^{10}$

The use of distilled water in previous studies ${ }^{18,19}$ was motivated by several reasons. From an experimental point of view, its fluid properties are well known, and it is readily available so that it provides a reference for other physical studies. This is particularly so since water spraying is applied in (de-)hydration studies involving human subjects ${ }^{1,7,8,10}$ and cadaver larynges. ${ }^{1,4,7}$ From a physiological point of view, water has similar density as reported for human saliva, ${ }^{9,20,21}$ and bi-directional water fluxes through the epithelium play an important role in regulating VF surface mucus hydration. ${ }^{1,22-24}$ Nevertheless, compared to human saliva, distilled water has a reduced dynamic viscosity. Therefore, the experiment and analysis described in Ref. 18 is first repeated for aqueousbased artificial saliva sprays in order to assess the effect of increased dynamic viscosity on the auto-oscillation.

In addition, previous experiments ${ }^{18,19}$ are re-assessed for upstream pressures near the oscillation onset threshold. Therefore, the experiment and analysis detailed in Ref. 18 are repeated for upstream driving pressures above the onset threshold in order to assess to which extent observations near the oscillation onset remain pertinent. In terms of human voice production, increasing the upstream or lung pressure corresponds to an increased vocal effort.

Both the upstream driving pressure and the dynamic viscosity of the spraying liquid might influence air-liquid fluid mixing. The fluid mixture determines the pressure distribution on the vocal folds walls within the glottal constriction. ${ }^{25}$ Consequently, the fluid-structure interaction and the resulting auto-oscillation might be affected. The upstream pressure during oscillation is analyzed considering features commonly studied in vocal folds analysis. ${ }^{18}$

Consequently, the aim of this work is to consider the validity of the findings reported in Ref. 18 for water spraying, first, when an aqueous-based spraying liquid with increased dynamic viscosity is used and, second, when the airflow pressure driving the FS interaction is increased above the one associated with the auto-oscillation onset.

\section{SPRAYED LIQUID FLUID PROPERTIES}

Three different spraying liquids are experimentally assessed in this work to mimic (re-)hydration: distilled water (Liq0) as in previous studies ${ }^{18,19}$ and two different aqueous-based liquids used in artificial saliva (AS) sprays, i.e., AS-Teijin (Liq1) and AS-Artisial (Liq2). The artificial sprays are commercially available in Japanese (for Liq1) and French (for Liq2) pharmacies, respectively. They are commonly used salines in order to remedy the lack of saliva by applying a burst of spray in the mouth (up to $4 \mathrm{ml}$ ). Both Liq1 and Liq2 are composed of different concentrations of sodium chloride, potassium chloride, and dipotassium phosphate. The liquid properties of interest (density $\rho$, dynamic viscosity $\mu$, surface tension $\sigma$, contact angles, and $\mathrm{pH}$ ) are determined at room temperature between $20^{\circ} \mathrm{C}$ and $22^{\circ} \mathrm{C}$ corresponding to temperatures for which experimental data are gathered. An overview is provided in Table I.

The density $\rho$ is found as the ratio between the mass and volume. The volume is quantified using a micro-pipette with accuracy $\pm 0.1 \mathrm{ml}$, and its mass is obtained using a precision balance with accuracy $\pm 0.01 \mathrm{~g}$. The tabulated $\rho$ values are the averages of 10 repetitions. ${ }^{26}$ The dynamic viscosity $\mu$ is obtained using a Cannon-Fenske viscometer with capillary diameters of $0.54 \mathrm{~mm}$ and $0.63 \mathrm{~mm}$. The tabulated $\mu$ values indicate the averages of four repetitions. ${ }^{26}$ The values for both artificial saliva sprays ( $L i q 1$ and Liq2) are compared with the values for distilled water (Liq0) and human saliva. 9,20,21 Densities $\rho$ for all assessed liquids (Liq0, Liq1, and Liq2) are approximately $1000 \mathrm{~kg} \mathrm{~m}^{-3}$, similar to the values reported for human saliva. Compared to distilled water ( $\operatorname{Liq} 0, \mu=1 \mathrm{mPa}$ ), dynamic viscosity $\mu$ is increased with approximately a factor of 5 for AS-Teijin (Liq1, $\mu=4.95 \mathrm{mPa}$ ) and a factor of 8 for AS-Artisial (Liq2, $\mu=7.44 \mathrm{mPa}$ s). It follows that whereas the viscosity of water is smaller than the range reported for human saliva, all assessed AS have $\mu$-values within the range reported for human saliva. Note that the AS properties are similar to those in recent fluid studies involving saliva in the oral cavity. ${ }^{27,28}$

The pendant drop method (drop generation with a syringe with diameter $1.7 \mathrm{~mm}$, MotionBlitz EoSens Cube camera, macro-lens) is applied to determine the air-liquid surface tension $\sigma$ using the Young-Laplace equation. ${ }^{29}$ The values for AS (Liq1 and Liq2) are calculated to approximate $\sigma=72 \mathrm{mN} / \mathrm{m}$ characterizing water (Liq0). Note that $\sigma \approx 72 \mathrm{mN} / \mathrm{m}$ obtained for all experimentally assessed liquids (Liq0, Liq1, and Liq2) is greater than the values reported for human saliva. ${ }^{9,21}$ For each liquid, the capillary length $\lambda_{c}$ is then

TABLE I. Properties of spraying liquids (Liq0, Liq1, and Liq2) and human saliva.

\begin{tabular}{lccccc}
\hline \hline & $\rho\left(\mathrm{kg} \mathrm{m}^{-3}\right)$ & $\mu(\mathrm{mPa} \mathrm{s})$ & $\sigma(\mathrm{mN} / \mathrm{m})$ & $\lambda_{c}(\mathrm{~mm})$ & $\mathrm{pH}(-)$ \\
\hline Saliva,20,21 & $\sim 1000$ & $2.75-15.5$ & $44-68$ & $2.1-2.6$ & $5.3-7.8$ \\
Water, Liq0 & 1000 & 1.00 & 72 & 2.7 & 6.80 \\
AS-Teijin, Liq1 & 1014 & 4.95 & 71 & 2.7 & 8.04 \\
AS-Artisial, Liq2 & 1015 & 7.44 & 72 & 2.7 & 6.72 \\
\hline \hline
\end{tabular}




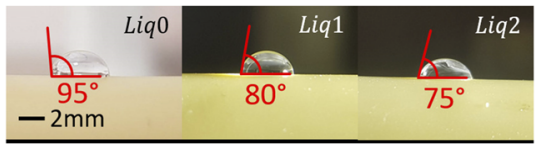

(a)

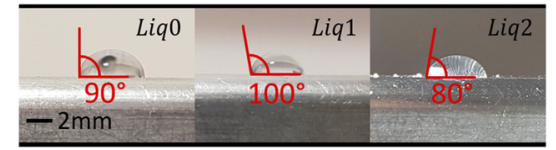

(b)
FIG. 2. Static contact angles $\theta_{s}$ measured for the experimentally assessed liquid droplets (water Liq0, AS-Teijin Liq1, and AS-Artisial Liq2) on the surfaces of (a) latex and (b) duralium. obtained as

$$
\lambda_{c}=\sqrt{\frac{\sigma}{\rho g}},
$$

with liquid density $\rho$ and gravitational constant $g=9.81 \mathrm{~m} / \mathrm{s}^{-2}$. The values are provided in Table I. As $\lambda_{c}=2.7 \mathrm{~mm}$ holds for all liquids, it is assumed that the sprayed liquid droplets are unaffected by gravity as $D_{n}<\lambda_{c}$ holds since the diameter $D_{n} \approx 0.7 \mathrm{~mm}$, given the spray nozzle diameter as indicated in Fig. 1. It is noted that this approximates $\lambda_{c}$ obtained for human saliva.

The wettability of the experimentally assessed spraying liquids (Liq0, Liq1, and Liq2) is assessed for latex and duralium surfaces. These surface materials are considered as they constitute the surfaces of the deformable (latex) and rigid (duralium) parts of the used experimental setup. The setup is schematically depicted in Fig. 1 and further detailed in Fig. 3. The static contact angles $\theta_{s}$ between the surface and a liquid droplet are shown in Fig. 2. All spraying liquids exhibit neutral wettability for these surface materials as static contact angles $\theta_{s}$ vary between $75^{\circ}$ and $100^{\circ} .^{30,31}$ Dynamic contact angles are measured for the least (water, Liq0) and the most viscous liquid (AS-Artisial, Liq2). The advancing $\theta_{a}$ and receding $\theta_{r}$ contact angles and their hysteresis $\theta_{a}-\theta_{r}$ are given in Table II. Similar values are obtained for both surfaces so that the values depend on the liquid. For both liquids, it is seen that the static contact angles $\theta_{s}$ approach the advancing contact angles $\theta_{a}$ to within $5^{\circ}$. The hysteresis doubles when comparing Liq0 to Liq2 as the receding contact angle is lowered. It is noted that the droplets used to test the wettability are smaller than the capillary length $\lambda_{c}=2.7 \mathrm{~mm}$ for all liquids as their diameter yields $1.7 \mathrm{~mm}$.

For completeness, the measured $\mathrm{pH}$ values for spraying liquids (calibrated potentiometric pH/ORP meter Hanna Instr. HI2211, accuracy \pm 0.01$)$ are given in Table I. The values are within the upper range reported for human saliva.

As contact angles, capillary lengths, and surface tensions are similar for all experimentally assessed liquids, surface wetting and droplet deposition are assumed similar. It follows that the properties

TABLE II. Overview of contact angles for water (Liq0) and AS-Artisial (Liq2).

\begin{tabular}{llccccc}
\hline \hline & & Static & & \multicolumn{3}{c}{ Dynamic } \\
\cline { 6 - 7 } \cline { 5 - 7 } & & $\begin{array}{c}\theta_{s} \\
(\mathrm{deg})\end{array}$ & & $\begin{array}{c}\theta_{a} \\
(\mathrm{deg})\end{array}$ & $\begin{array}{c}\theta_{r} \\
(\mathrm{deg})\end{array}$ & $\begin{array}{c}\theta_{a}-\theta_{r} \\
(\mathrm{deg})\end{array}$ \\
\hline \multirow{2}{*}{ Water, Liq0 } & Latex & 95 & & 98 & 77 & 21 \\
& Duralium & 90 & & 94 & 72 & 22 \\
\hline \multirow{2}{*}{ AS-Artisial, Liq2 } & Latex & 75 & & 80 & 35 & 45 \\
& Duralium & 80 & & 85 & 44 & 41 \\
\hline \hline
\end{tabular}

of the experimentally assessed aqueous-based artificifial saliva sprays AS-Teijin (Liq1) and AS-Artisial (Liq2) have similar properties as water, except for an increased dynamic viscosity $\mu$. As such, these fluids allow us to study the influence of increased dynamic viscosity within the range pertinent to human saliva.

\section{EXPERIMENTAL APPROACH}

Auto-oscillation due to a fluid-structure interaction is generated by supplying airflow through a rigid channel (duralium, internal diameter $25 \mathrm{~mm}$, neutral wettability) containing a deformable channel portion as a mechanical VF replica is inserted. The setup depicted in Fig. 1 is fully detailed in Ref. 18. Briefly, the deformable pressurized latex tube (PLT) VF replica (neutral wettability), illustrated in Fig. 3, consists of two pressurized latex tubes (thickness $0.2 \mathrm{~mm}$, inferior-superior length $H=12 \mathrm{~mm}$, and posterioranterior length $w=25 \mathrm{~mm}$ ) representing the left and right VF. ${ }^{18,26,32}$ These VF tubes are connected to a water column with a controllable height so that their internal pressure $P_{P L T}$, which determines its elasticity, can be varied. Both VFs are placed face to face in a metallic frame. The initial spacing between both VFs in the absence of airflow ranges from $30 \mathrm{~mm}^{2}$ up to $70 \mathrm{~mm}^{2}$ and results from the swelling of the latex tubes due to the imposed internal pressure $P_{P L T}$ and from adjusting the micrometric screws. During VF auto-oscillation along the transverse right-left direction, the spacing between both VFs varies with time so that, in general, $A_{c}(t) \leq 100 \mathrm{~mm}^{2}$ holds. ${ }^{32} \mathrm{~A}$ central latex tube (diameter $30 \mathrm{~mm}$ and thickness $0.2 \mathrm{~mm}$ ) is placed between both VFs. This central latex tube is fixed to the upstream (streamwise length $11 \mathrm{~cm}$, inferior of VFs) and downstream (streamwise length $12 \mathrm{~cm}$, superior of VFs) channel portions representing the vocal tract and trachea, respectively, so that the airflow passes through without leakage. The replica is manually assembled so that the exact values depend on the montage $(\mathcal{M})$.

When airflow passes through the gap between both tubes, a fluid-structure interaction leads to auto-oscillation in the same way as during human phonation. Steady airflow (density $\rho_{G}$ $=1.2 \mathrm{~kg} \mathrm{~m}^{3}$, dynamic viscosity $\mu_{G}=1.8 \times 10^{-5} \mathrm{~Pa} \mathrm{~s}$, and temperature $22^{\circ} \mathrm{C} \pm 2{ }^{\circ} \mathrm{C}$ ) is continuously provided to the flow channel along the streamwise inferior-superior direction by an air compressor (Atlas Copco GA5 FF-300-8, GA15 FF-8) connected to an upstream pressure reservoir (volume $0.22 \mathrm{~m}^{3}$ ) filled with acoustic foam in order to avoid parasitic acoustic resonances and controlled with a valve (Norgren, 11-818-987). A pressure transducer (Endevco $8507 \mathrm{C}-5$, accuracy $\pm 5 \mathrm{~Pa}$ ) is positioned in a pressure tap situated $65 \mathrm{~mm}$ upstream of the VF replica in order to measure the upstream pressure $P_{u}(t)$. During experiments, the mean upstream pressure $\bar{P}_{u}$ yields at least the auto-oscillation onset pressure $P_{\text {Onset }}$, which is the minimum upstream pressure required to sustain autooscillation for the VF replica in the dry configuration before liquid spraying. 


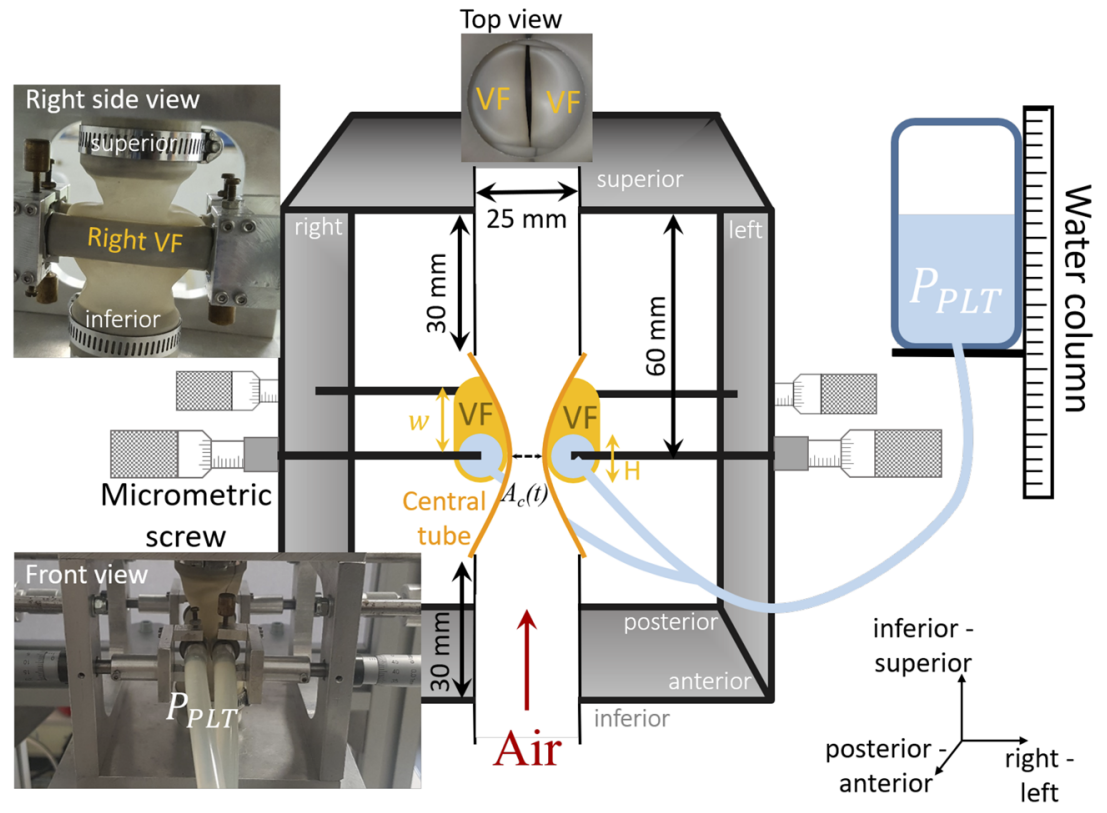

FIG. 3. Overview of the deformable pressurized latex tube (PLT) VF replica.
Liquid is sprayed at the downstream end of the flow channel, i.e., the downstream vocal tract outlet, in the superior-inferior direction, as depicted in Fig. $1 .{ }^{18}$ Note that this corresponds to the natural usage of AS sprays during which a spray burst is supplied through the mouth. Liquids discussed in Sec. II (Liq0, Liq1, or Liq2) are homogeneously sprayed by manually emptying a graduated syringe (accuracy $0.5 \mathrm{ml}$ ) with a known volume $V_{L} \leq 5 \mathrm{ml}$. The syringe is equipped with a common spray nozzle (diameter $D_{n}=0.7 \mathrm{~mm}$ $\pm 0.1 \mathrm{~mm}$, length $10 \mathrm{~mm}$, and diffusion angle $\left.20^{\circ}\right)$. During experiments, liquid spraying is time-tagged $t_{L}(t)$ by manually operating an electrical switch at the start and end of each spray burst so that its duration $\Delta t_{L}$ corresponds to $t_{L}(t)>0$. An overview of sprayed liquid volume $V_{L}$, spray duration $\Delta t_{L}$, liquid flow rate $\Phi_{L}$, and jet bulk velocity at the nozzle exit $U_{L}$ is given in Table III. Overall, liquid spraying has mean duration $\bar{\Delta}_{t}=1.62 \pm 0.6 \mathrm{~s}, \Delta t_{L}<3 \mathrm{~s}$, mean liquid volume flow rate $\bar{\Phi}_{L}=1.75 \pm 0.40 \mathrm{ml} / \mathrm{s}$, and mean jet bulk velocity $\bar{U}_{L}=4.55 \pm 1.02 \mathrm{~m} / \mathrm{s}$.

The magnitudes and liquid properties given in Table I allow us to estimate the Weber number $W e$,

$$
W e=\frac{\rho U_{L}^{2} D_{n}}{\sigma},
$$

and droplet relaxation time $t_{d}$

$$
t_{d}=\frac{\rho D_{n}^{2}}{18 \mu_{G}},
$$

for droplets with diameter $D_{n}$. For each of the assessed liquids ( $L i q_{0}$, $L i q_{1}$, and $L i q_{2}$ ), $W e \approx 212 \pm 90$ and $t_{d} \approx 1.5 \mathrm{~s}$ hold, which is the same magnitude as observed for human saliva (Table IV). Sprayed liquid jets are thus expected to break up into much smaller droplets as their diameter decreases, which favors mixing with the airflow. It follows that the Stokes number,

$$
S t k=\frac{t_{d} U_{G}}{H},
$$

varies with $U_{G}$ during the opening and closing phase of a single oscillation cycle, regardless of the assessed liquid. Mixing of the droplets with the airflow is expected when Stk is less than unity and surface hydration due to droplet deposition when Stk exceeds unity.

Temporal signals $P_{u}(t)$ and $t_{L}(t)$ are acquired (PC/DAQ, National Instruments PCI-MIO-16XE-10) with a sampling frequency of $10 \mathrm{kHz}$. The representative time traces of upstream pressure $P_{u}(t)$ and time tag $t_{L}(t)$ for a typical auto-oscillation experiment are shown in Fig. 4. During the first dry stage, $10 \mathrm{~s}$ steady-state

TABLE III. Overview of sprayed liquid volumes $V_{L}$, spray duration $\Delta t_{L}$, liquid volume flow rate $\Phi_{L}$, and liquid jet bulk velocity $U_{L}$.

\begin{tabular}{lccccc}
\hline \hline$V_{L}(\mathrm{~mL})$ & 1 & 2 & 3 & 4 & 5 \\
\hline$\Delta t_{L}(\mathrm{~s})$ & $0.82 \pm 0.02$ & $1.31 \pm 0.08$ & $1.70 \pm 0.16$ & $1.84 \pm 0.18$ & $2.41 \pm 0.14$ \\
$\Phi_{L}\left(\mathrm{~m}^{3} / \mathrm{s}\right)$ & $1.22 \times 10^{-6}$ & $1.52 \times 10^{-6}$ & $1.77 \times 10^{-6}$ & $2.18 \times 10^{-6}$ & $2.08 \times 10^{-6}$ \\
$U_{L}(\mathrm{~m} / \mathrm{s})$ & 3.18 & 3.96 & 4.56 & 5.67 & 5.40 \\
\hline \hline
\end{tabular}


TABLE IV. Droplet properties for liquid spraying (Liq0, Liq1, and Liq2) and human saliva.

\begin{tabular}{|c|c|c|c|c|c|c|}
\hline & \multicolumn{5}{|c|}{$W e(-)$} & \multirow{2}{*}{$\frac{t_{d}(\mathrm{~s})}{V_{L} \in[15] \mathrm{m}}$} \\
\hline & $V_{L}=1 \mathrm{ml}$ & $V_{L}=2 \mathrm{ml}$ & $V_{L}=3 \mathrm{ml}$ & $V_{L}=4 \mathrm{ml}$ & $V_{L}=5 \mathrm{ml}$ & \\
\hline Water, Liq0 & 98 & 152 & 202 & 313 & 284 & 1.51 \\
\hline AS-Teijin, Liq1 & 101 & 157 & 208 & 321 & 292 & 1.53 \\
\hline AS-Artisial, Liq2 & 100 & 155 & 205 & 317 & 288 & 1.53 \\
\hline Saliva ${ }^{9,20,21}$ & & & $100-500$ & & & 1.51 \\
\hline
\end{tabular}

auto-oscillation is gathered to characterize the dry configuration (subscript dry, $V_{L}=0 \mathrm{ml}$ ). The second stage corresponds to liquid spraying characterized by the used liquid (Liq0, Liq1, or Liq2) and sprayed volume $V_{L}$. The third stage of $5 \mathrm{~s}$, which yields about 3.3 times the droplet relaxation time $t_{d}$, allows stabilization after liquid spraying. The fourth liquid stage of $10 \mathrm{~s}$ is analyzed to study the effect of liquid spraying on the auto-oscillation established during the dry stage.

Mean upstream pressure $\bar{P}_{u}$ during the dry stage (only airflow) provides an overestimation of the supplied airflow volume flow rate $Q_{\max , d r y}$ as

$$
Q_{\max , d r y}=\sqrt{\frac{2 \bar{P}_{u}}{\rho_{G}}} A_{c, \max } \cdot c_{s},
$$

with maximum constriction area $A_{c, \max }=100 \mathrm{~mm}^{2}$ and constant $c_{s}=1.3$ accounting for flow detachment and jet formation along the diverging part of the glottal constriction. ${ }^{33}$ An upper limit of THE Reynolds number $R e_{d r y}$ characterizing the dry stage is then obtained as

$$
R e_{d r y}=\frac{\rho_{G} Q_{\max , d r y}}{\mu_{G} w},
$$

with posterior-anterior VF length $w=25 \mathrm{~mm}$, as depicted in Fig. 3. The Strouhal number $S r_{d r y}$ of the oscillating flow during the dry stage is then estimated from the oscillation frequency $f_{0}$ as

$$
S r_{d r y}=\frac{f_{0} H}{Q_{\max , d r y}} A_{c, \max } \cdot c_{s},
$$

with inferior-superior VF length $H=12 \mathrm{~mm}$, as indicated in Fig. 3 .

In the dry stage $\left(V_{L}=0 \mathrm{ml}\right)$, both $P_{\text {Onset }}$ and the associated oscillation frequency $f_{\text {Onset }}$ depend on the imposed elasticity

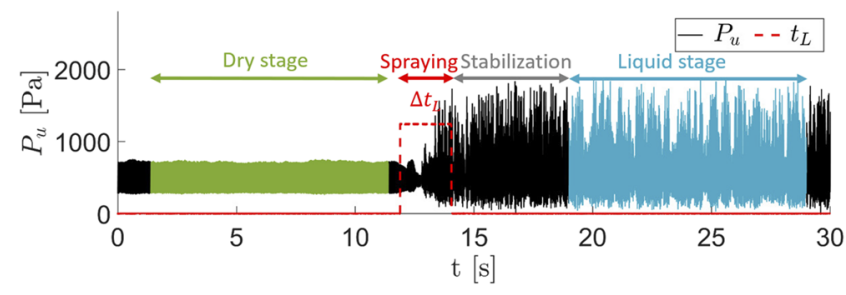

FIG. 4. Representative time traces of $P_{u}(t)$ and $t_{L}(t)$ indicating the consecutive stages: dry stage $\left(10 \mathrm{~s}, V_{L}=0 \mathrm{ml}\right)$, spraying stage (duration $\left.\Delta t_{L}, V_{L} \leq 5 \mathrm{ml}\right), 5 \mathrm{~s}$ stabilization, and liquid stage (10 s). The dry and liquid stages are analyzed. condition $P_{P L T}$, as illustrated in Fig. 5. Upstream threshold pressures [Fig. 5(a)] at the auto-oscillation onset $P_{\text {Onset }}$ and offset $P_{\text {Offset }}$ exhibit a minimum due to changes in the initial glottal area and damping of mechanical resonances. ${ }^{12}$ The minimum is obtained at $P_{P L T} \approx 3.3$ $\mathrm{kPa}$ for PLT VF replica montage $\mathcal{M} I$ [Fig. 5(a)]. The oscillation frequency $f_{\text {Onset }}\left[\right.$ [Fig. 5(b)] increases quasi-linearly with $P_{P L T}$ due to the increase in mechanical resonance frequencies $f_{1,2}^{M}$ measured from the frequency-response functions. ${ }^{18,26}$ The observed auto-oscillation threshold pressures $P_{\text {Onset, }}$ Offset and oscillation frequencies $f_{\text {Onset, Offset }}$ are within the range characterizing a normal human voice. ${ }^{34}$

Liquid spraying is experimentally assessed for several elasticity conditions $P_{P L T}$, corresponding to vertical lines in Fig. 5, so that $P_{\text {Onset }}$ and $f_{\text {Onset }}$ characterizing the dry stage vary. In addition, the exact values vary as experiments are performed for two different PLT VF replica montages, labeled $\mathcal{M} I$ and $\mathcal{M} I$.

The experimental conditions to study the influence of the dynamic viscosity of the sprayed liquid (liquid viscosity experiment) are summarized in Table V. For each spraying liquid (Liq0, Liq1, and

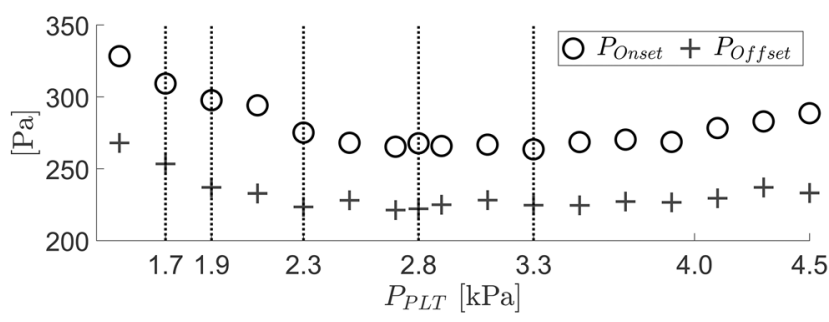

(a)

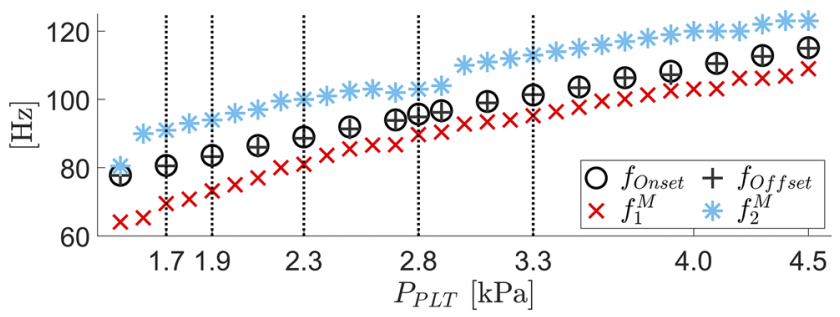

(b)

FIG. 5. Auto-oscillation onset $(\bigcirc)$ and offset $(+)$ values as a function of elasticity condition $P_{P L T}$ during the dry stage $\left(V_{L}=0 \mathrm{ml}\right)$ for PLT VF replica montage $(\mathcal{M I})$ : (a) upstream threshold pressures $P_{\text {Onset }}$ and $P_{\text {Offset }}$ and (b) oscillation frequencies $f_{\text {Onset }}$ and $f_{\text {Offset }}$. Mechanical resonance frequencies $f_{1}^{M}$ and $f_{2}^{M}$ are given. Vertical lines indicate $P_{P L T}$ for which the liquid is sprayed. 
TABLE V. Overview of the liquid viscosity experiment

\begin{tabular}{lccccc}
\hline \hline $\mathcal{M}$ & $P_{P L T}(\mathrm{kPa})$ & $R e_{d r y}$ & $S r_{d r y}$ & Liquid & $V_{L}(\mathrm{~mL})$ \\
\hline$I$ & 2.8 & 8950 & 0.05 & Liq0, Liq1, Liq2 & $(1-5)$ \\
$I$ & 3.3 & 7800 & 0.06 & Liq0, Liq1, Liq2 & $(1-5)$ \\
\hline \hline
\end{tabular}

TABLE VI. Overview of the airflow experiment.

\begin{tabular}{lccccc}
\hline \hline $\mathcal{M}$ & $P_{P L T}(\mathrm{kPa})$ & $R e_{d r y}$ & $S r_{d r y}$ & Liquid & $V_{L}(\mathrm{ml})$ \\
\hline$I I$ & 1.7 & $5200-7500$ & $0.11-0.078$ & Liq0 & 4 \\
II & 1.9 & $5200-7500$ & $0.11-0.078$ & Liq0 & 4 \\
II & 2.3 & $5200-7500$ & $0.11-0.078$ & Liq0 & 4 \\
II & 2.8 & $5200-7500$ & $0.11-0.078$ & Liq0 & 4 \\
I & 3.3 & $7000-8300$ & $0.060-0.023$ & Liq0, Liq2 & 3 \\
\hline \hline
\end{tabular}

Liq2), the sprayed volume $V_{L}$ is varied. The experiment is repeated for two $\left(P_{P L T}, R e_{d r y}\right)$-combinations for PLT VF replica montage $\mathcal{M} I$.

Experimental conditions to study the influence of increasing the upstream driving pressure $\bar{P}_{u}$ (airflow experiment) and hence $R e_{d r y}[$ [Eq. (6)] during the dry phase are summarized in Table VI. For each assessed $\left(P_{P L T}, V_{L}\right)$-combination, $R e_{d r y}$ is increased from 5200 up to $7500\left(\approx 45 \% R e_{d r y}\right.$ increase, $L i q 0, V_{L}=4 \mathrm{ml}$, replica montage $\mathcal{M} I I)$ or from 7000 up to $8000\left(\approx 15 \% R e_{d r y}\right.$ increase, Liq0 and Liq2, $V_{L}=3 \mathrm{ml}$, replica montage $\left.\mathcal{M} I\right)$.

For all experiments, $S r_{d r y} \leq 0.11$ holds and $R e_{d r y}$ is obtained by varying $\bar{P}_{u}$ in the range of $120 \mathrm{~Pa}$ up to $400 \mathrm{~Pa}$. The orders of magnitudes of $S r_{d r y}$ and $R e_{d r y}$ are within the range associated with normal human voice production. ${ }^{34-36}$

\section{UPSTREAM PRESSURE ANALYSIS}

Ten second portions of upstream pressure $P_{u}(t)$ of the dry and liquid stages indicated in Fig. 4, corresponding to $N_{p}$ oscillation cycles with $N_{p}>400$, are analyzed. The mean oscillation characteristics and their fluctuations are objectively quantified following the approach detailed in Ref. 18. It is outlined in the Introduction that these features are assessed due to their use in clinical studies to express vocal effort and voice quality. ${ }^{2-8}$

A cycle-to-cycle analysis is performed in order to retrieve the peak-to-peak amplitude $\mathcal{A}$ and period $T$ for each oscillation cycle from which their arithmetic means $\overline{\mathcal{A}}$ and $\bar{T}$ are obtained. The cycle-to-cycle perturbations of amplitude $\zeta_{\mathcal{A}}$ and period $\zeta_{T}$ are obtained as

$$
\zeta_{\mathcal{X}}=\frac{\frac{1}{N_{p}-1} \sum_{i=1}^{N_{p}-1}\left|\mathcal{X}_{i}-\mathcal{X}_{i+1}\right|}{\overline{\mathcal{X}}},
$$

with $\mathcal{X}=\mathcal{A}$ for the amplitude perturbations and $\mathcal{X}=T$ for the period perturbations. Note that, in voice quality studies, $\zeta_{\mathcal{A}}$ and $\zeta_{T}$ are labeled shimmer and jitter, respectively.

The overall harmonic content of $P_{u}(t)$ is quantified considering the total harmonic distortion rate THD and the signal-to-noise ratio SNR. The THD compares the summed power of harmonic frequencies $\mathcal{P}_{\text {harm }}$ with the power of the lowest harmonic frequency $\mathcal{P}_{f_{N}}$ as

$$
T H D=10 \log _{10}\left(\frac{\mathcal{P}_{\text {harm }}}{\mathcal{P}_{f_{N}}}\right) .
$$

The SNR compares the ratio of the summed power of all signal harmonics $\mathcal{P}_{\text {signal }}$ to the summed power of the remaining noise $\mathcal{P}_{\text {noise }}$ as

$$
S N R=10 \log _{10}\left(\frac{\mathcal{P}_{\text {signal }}}{\mathcal{P}_{\text {noise }}}\right) .
$$

Besides these general spectral features, the oscillation frequency $f_{N}$ is quantified. As in Ref. 18, two oscillation frequencies are considered. First, $f_{N} \approx f_{0}$, where $f_{0}$ indicates the first harmonic frequency observed in the dry stage. Second, a quasi-subharmonic frequency $f_{N} \approx f_{0.5}$ due to period doubling in the liquid stage can appear so that $f_{0.5} \approx f_{0} / 2.18,19$

\section{RESULTS}

The features obtained for the liquid viscosity experiment (Sec. V A) and the airflow experiment (Sec. V B) are presented.

\section{A. Liquid viscosity experiment}

The experiments summarized in Table $V$ for $V_{L}>0 \mathrm{ml}$ allow us to compare the influence of spraying water (Liq0) with the influence of spraying artificial saliva sprays, AS-Teijin (Liq1) and AS-Artisial (Liq2). As a reference, the features obtained during the dry stage, i.e., without liquid spraying for $V_{L}=0 \mathrm{ml}$, are considered as well. The dynamic viscosity $\mu$ of water (Liq0) is increased by a factor of 4 using AS-Teijin (Liq1) and 8 using AS-Artisial (Liq2), as indicated in Table I. For each liquid, the features are plotted as a function of sprayed volume $V_{L}$. To avoid overlapping markers, the AS feature values are shifted around $V_{L}$.

The oscillation frequencies $f_{N}\left(V_{L}\right)$ for elasticity conditions $P_{P L T}$ $\epsilon\{2.8,3.3\} \mathrm{kPa}$ are plotted in Fig. 6 . The first harmonic frequency $f_{0}$ is only marginally affected as liquid spraying results in a slight decrease $(<2 \%)$ from $f_{0} \approx 102 \mathrm{~Hz}$ characterizing $V_{L}=0 \mathrm{ml}$ in accordance with Fig. 5(b). On the other hand, a near subharmonic frequency $f_{0.5}$ for $V_{L} \geq 1 \mathrm{ml}$ is generated associated with period doubling as previously observed for water spraying. ${ }^{18,19}$ The impact of dynamic viscosity on oscillation frequencies $f_{N}$ is thus limited as same phenomena are observed, regardless of the sprayed liquid.

The mean upstream pressure $\bar{P}_{u}$ (Fig. 7) and peak-to-peak cycle amplitude $\overline{\mathcal{A}}\left(V_{L}\right)$ (Fig. 8) show an overall increase. For all liquids, a transition occurs from the dry configuration for $V_{L}=0 \mathrm{ml}$ up to a plateau reached in the range $V_{L} \geq 3 \mathrm{ml}$. Within the plateau, $\bar{P}_{u}$ augments with $\approx 100 \mathrm{~Pa}$ for both $P_{P L T}$, whereas the increase in $\overline{\mathcal{A}}$ depends on the elasticity and on the sprayed liquid. Although the liquid does not affect the general tendency, the increase tends to be limited or delayed with dynamic viscosity so that $\bar{P}_{u}$ and $\overline{\mathcal{A}}\left(V_{L}\right)$ are smallest for Liq2 (AS-Artisial) within the transition region when $1 \leq V_{L} \leq 2 \mathrm{ml}$. In the transition range, air-liquid mixing determines the flow behavior, whereas for $V_{L} \geq 3 \mathrm{ml}$, liquid flow is expected to dominate the flow. ${ }^{25}$ The found influence of dynamic viscosity is of particular interest for human voice production. The reduced 


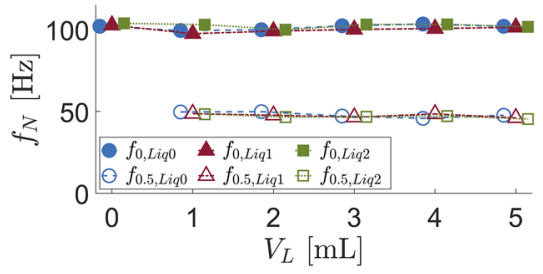

(a)

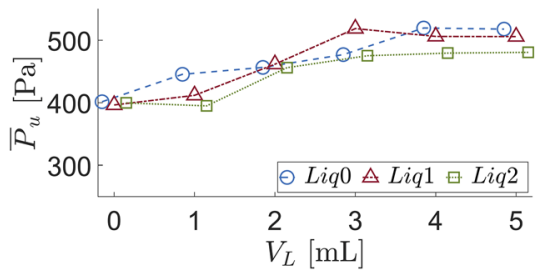

(a)

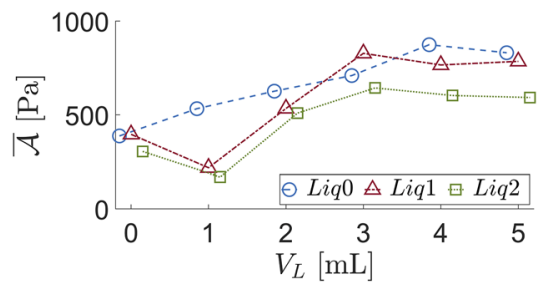

(a)

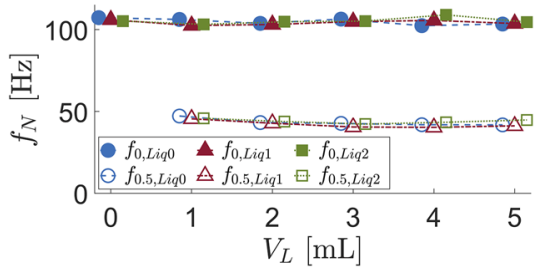

(b)

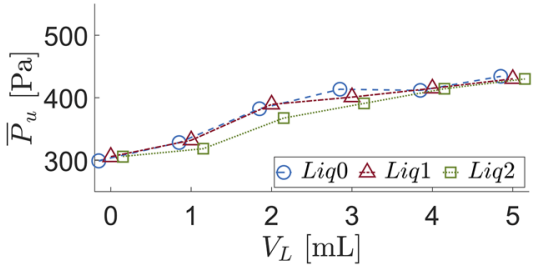

(b)

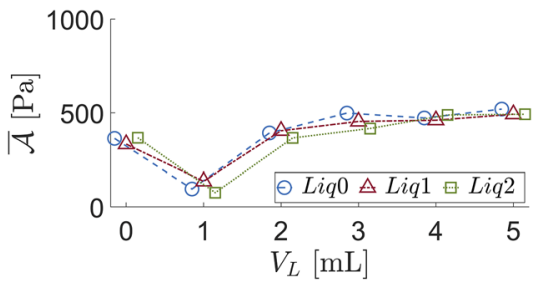

(b)
FIG. 6. Oscillation frequency $f_{N}\left(V_{L}\right)$ for all liquids (Liq0, Liq1, and Liq2) with the first harmonic $f_{N}=f_{0}$ (filled markers) or $f_{N}$ $=f_{0.5}$ (empty markers): (a) $P_{P L T}=2.8 \mathrm{kPa}$ and (b) $P_{P L T}=3.3 \mathrm{kPa}$.
FIG. 7. Mean upstream pressure $\bar{P}_{u}\left(V_{L}\right)$ for all liquids (Liq0, Liq1, and Liq2): (a) $P_{P L T}=2.8 \mathrm{kPa}$ and (b) $P_{P L T}=$ $3.3 \mathrm{kPa}$.
FIG. 8. Mean peak-to-peak cycle amplitude $\overline{\mathcal{A}}\left(V_{L}\right)$ for all liquids (Liq0, Liq1, and Liq2): (a) $P_{P L T}=2.8 \mathrm{kPa}$ and (b) $P_{P L T}=3.3 \mathrm{kPa}$. upstream pressure $\bar{P}_{u}$ and amplitude $\overline{\mathcal{A}}$ are considered beneficial for human voice as the auto-oscillation requires less effort and less impact. Furthermore, $\overline{\mathcal{A}}\left(V_{L}\right)$ shows a minimum at $V_{L}=1 \mathrm{ml}$ for Liq1 and Liq2 suggesting that an optimal voice condition exists, which, for the used replica, is reached for $V_{L} \approx 1 \mathrm{ml}$. It is noted that these general tendencies do not hold at $P_{P L T}=2.8 \mathrm{kPa}$ for Liq 1 at $V_{L}=3 \mathrm{ml}$ as $\bar{P}_{u}$ (Fig. 7) and $\overline{\mathcal{A}}\left(V_{L}\right)$ (Fig. 8) are increased, with $\approx 35 \mathrm{~Pa}$ and $\approx 120 \mathrm{~Pa}$, respectively, compared to the values obtained for Liq 0 at $V_{L}=3 \mathrm{ml}$. This is argued to be due to the influence of the liquid's viscosity on the liquid-air fluid mixing, which, in turn, determines the extent of the transition zone and hence the $V_{L}$ associated with the plateau onset, which seems to shift to lower $V_{L}$ as the liquid viscosity increases. This mechanism remains to be detailed and confirmed in future research.

The cycle-to-cycle perturbation of the mean quantities discussed so far is considered. Note that the reduced cycle-to-cycle perturbation improves voice quality as well. The cycle-to-cycle perturbation curves of amplitude $\zeta_{\mathcal{A}}\left(V_{L}\right)$ (Fig. 9) and period $\zeta_{T}\left(V_{L}\right)$ (Fig. 10) express that liquid spraying $V_{L}>0 \mathrm{ml}$ introduces perturbation as $\zeta_{\mathcal{A}, T}>20 \%$ holds compared to $\zeta_{\mathcal{A}, T}<4 \%$ for $V_{L}=0$ $\mathrm{ml}$ (dry). As for mean features $\bar{P}_{u}$ and $\overline{\mathcal{A}}$, the perturbation curves exhibit a transition zone for $0<V_{L}<3$ and a stable plateau zone for $V_{L} \geq 3 \mathrm{ml}$. The perturbation degree is this large for all liquids due to period doubling associated with a loss of determinism described

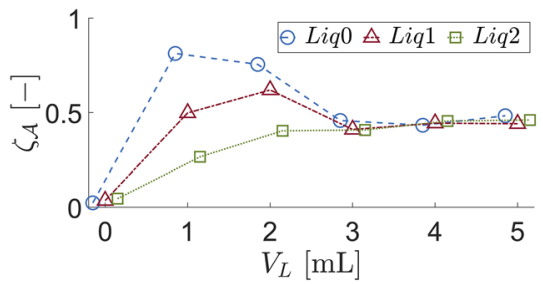

(a)

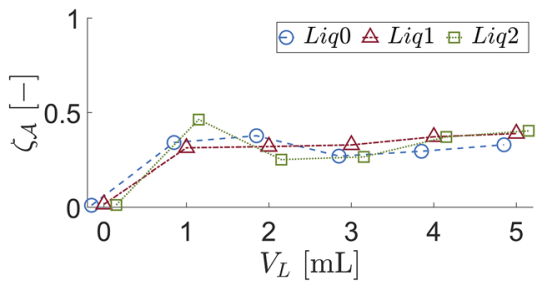

(b)
FIG. 9. Cycle-to-cycle amplitude perturbation $\zeta_{A}\left(V_{L}\right)$ for all liquids (LiqO, Liq1, and Liq2): (a) $P_{P L T}=2.8 \mathrm{kPa}$ and (b) $P_{P L T}=3.3 \mathrm{kPa}$. 


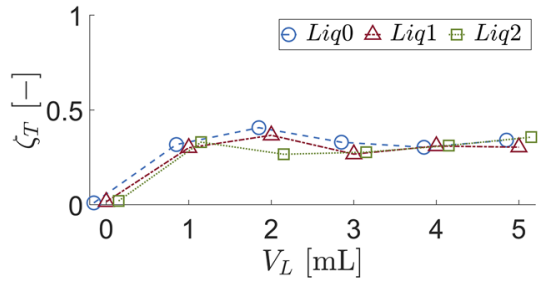

(a)

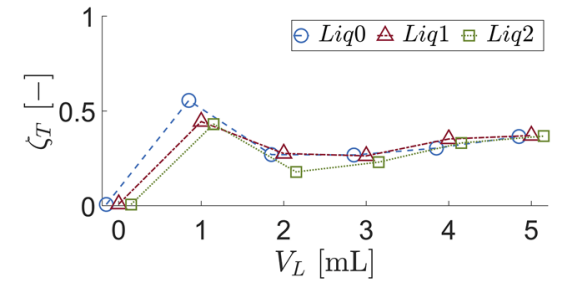

(b) for water spraying in Ref. 19. Nevertheless, as for mean $\bar{P}_{u}$ and $\overline{\mathcal{A}}$, increased viscosity provides again some regulation as it tends to limit the perturbation in the transition zone. The degree of perturbation decreases with liquid viscosity in the transition zone. This is most clearly observed considering $\zeta_{\mathcal{A}}\left(V_{L}\right)$ (Fig. 9) for $P_{P L T}=2.8 \mathrm{kPa}$. As a maximum perturbation is found in the transition zone, it is of future interest to decrease the $V_{L}$-increment to refine the analysis in the transition zone. This is of particular interest considering elasticity conditions for which differences between liquids are less pronounced as is the case for $P_{P L T}=3.3 \mathrm{kPa}$. It is hypothesized that the different sensitivity to the liquid viscosity observed between elasticity conditons $P_{P L T}=2.8 \mathrm{kPa}$ and $P_{P L T}=3.3 \mathrm{kPa}$ is related to difference in stability of the auto-oscillation in the dry configuration. Supposing that a less stable auto-oscillation is more easily to be affected, it is suggested that the auto-oscillation at $V_{L}=0 \mathrm{ml}$ is more stable for $P_{P L T}=3.3 \mathrm{kPa}$ than for $P_{P} L T=2.8 \mathrm{kPa}$. Note that this is reasonable, given the increased Reynolds number needed for $P_{P L T}$ $=2.8 \mathrm{kPa}\left(R e_{d r y}=8950\right)$ compared to $P_{P L T}=3.3 \mathrm{kPa}\left(R e_{d r y}=7800\right)$ (Table V).

The regulating capacity of dynamic viscosity $\mu$ in the transition zone for $0<V_{L}<3 \mathrm{ml}$ is also apparent considering the total harmonic distortion rate $T H D\left(V_{L}\right)$ (Fig. 11) and signal-to-noise ratio $\operatorname{SNR}\left(V_{L}\right)$ (Fig. 12) as the decrease in both THD and SNR reduces with $\mu$. It is noted that the imposed elasticity condition $P_{P L T}$ affects the magnitude of observed tendencies as differences are again more pronounced for $P_{P L T}=2.8 \mathrm{kPa}$ than for $P_{P L T}=3.3 \mathrm{kPa}$.

\section{B. Airflow experiment}

The influence of the airflow applied during the dry stage on the analysis stage is assessed from the experimental conditions summarized in Table VI. For each $P_{P L T}$ condition, the features are plotted as a function of $R e_{d r y}$ defined in Eq. (6). For clarity, the values for different $P_{P L T}$ are shifted around each $R e_{d r y}$. In this section, each figure legend consists of multiple columns with three row entries. Each column corresponds to the same elasticity condition $P_{P L T}$ indicated in the first row and represented in the figure by a unique symbol. The empty symbol in the second row entry corresponds to the dry condition $V_{L}=0 \mathrm{ml}$. The filled symbol in the third row entry corresponds to liquid spraying so that the imposed $V_{L}$ or/and spraying liquid is indicated.

\section{Influence of Re dry: Water (Liq0)}

First, the dry and liquid stages are analyzed for water (Liq0) spraying at $V_{L}=4 \mathrm{ml}$ for PLT VF replica montage $\mathcal{M} I I$ in Table VI. This is motivated from Sec. V A as features for water overlap with

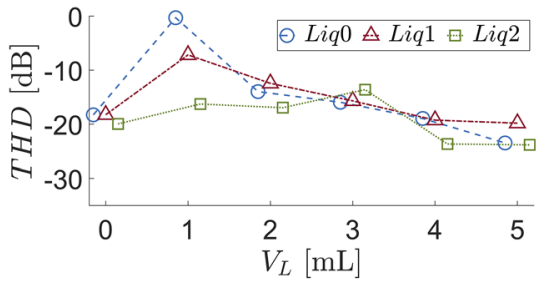

(a)

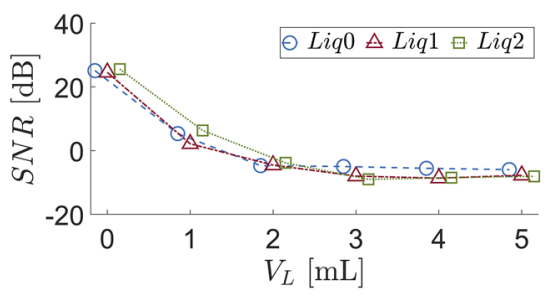

(a)

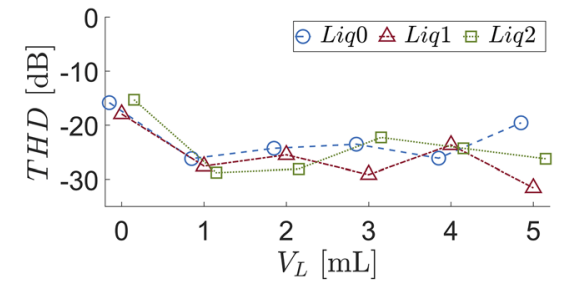

(b)

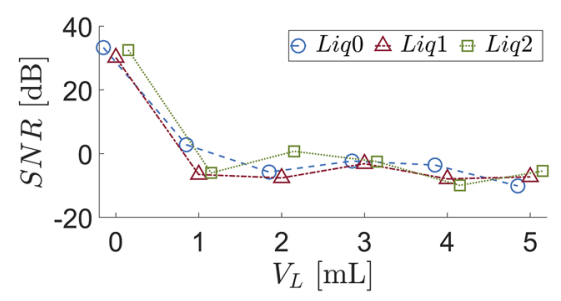

(b)
FIG. 11. Total harmonic distortion rate $T H D\left(V_{L}\right)$ for all liquids ( $L i q 0, L i q 1$, and Liq2): (a) $P_{P L T}=2.8 \mathrm{kPa}$ and (b) $P_{P L T}=$ $3.3 \mathrm{kPa}$. 


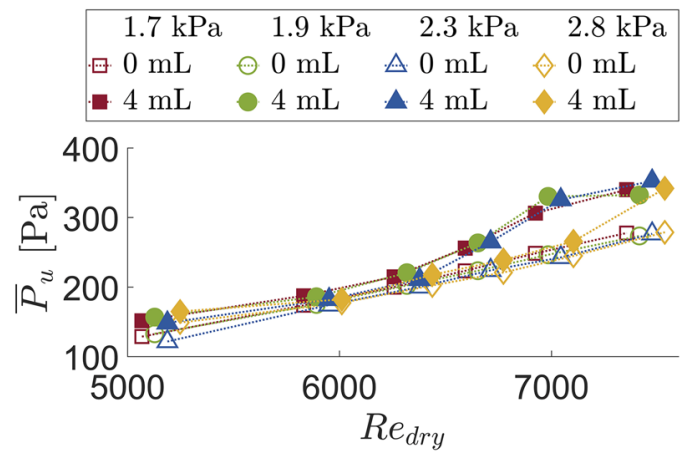

FIG. 13. Mean upstream pressure $\bar{P}_{u}\left(R e_{d r y}\right)$ for different $P_{P L T}(\mathrm{kPa}$, symbols) in the dry (empty) and liquid (filled) stages for water (Liq0) spraying with $V_{L}=4 \mathrm{ml}$.

those obtained for AS for $V_{L} \geq 3 \mathrm{ml}$. The mean upstream pressures $\bar{P}_{u}$ are plotted in Fig. 13. For $R e_{d r y} \approx 5200$, the imposed $\bar{P}_{u}$ values in the dry stage are near the oscillation onset pressures so that $\bar{P}_{u} \approx P_{\text {Onset }}$, regardless of $P_{P L T}$. In general, the mean upstream pressures $\bar{P}_{u}$ observed during the liquid stage are greater than the values observed during the dry stage. For $R e_{d r y} \leq 6500$, the increase in $\bar{P}_{u}$ with $R e_{d r y}$ observed during the liquid stage occurs at the same rate as the increase imposed during the dry stage for all elasticity conditions $P_{P L T}$. For $R e_{d r y}>6500$, the increase accelerates until it yields about $100 \mathrm{~Pa}$. The increase is hypothesized to reflect the loss of stability and eventually the turbulent nature of the air-liquid fluid mixture for $R e_{d r y}>6500$, which needs to be further investigated in the future. The precise $R e_{d r y}$ at which $\bar{P}_{u}$ starts to increase depends on the elasticity condition $P_{P L T}$. The plotted curves in Fig. 13 suggest that increasing $P_{P L T}$ delays the increase to larger $R e_{d r y}$. This is expected from the decreasing onset pressure thresholds in this $P_{P L T^{-}}$ range [shown in Fig. 5(a)], suggesting that the oscillation stability increases with $P_{P L T}$ so that higher $R e_{d r y}$ are needed to generate turbulence. It is noted that the increase in $\bar{P}_{u}$ with $100 \mathrm{~Pa}$ between the $\operatorname{dry}\left(V_{L}=0 \mathrm{ml}\right)$ and liquid stages at $V_{L}=4 \mathrm{ml}$ is consistent with the observations plotted in Fig. 7 for both $P_{P L T}=2.8 \mathrm{kPa}\left(R e_{d r y} \approx 8950\right.$ in Table V) and $P_{P L T}=3.3 \mathrm{kPa}\left(R e_{d r y} \approx 7800\right.$ in Table V).

The auto-oscillation frequencies $f_{N}\left(R e_{d r y}\right)$ are plotted in Fig. 14(a). For $\bar{P}_{u} \approx P_{\text {Onset }}$, water spraying causes the auto-oscillation to cease so that no features (filled symbols) are plotted for low $R e_{d r y}$. In the dry stage, the oscillation frequency $f_{N}=f_{0}$ exhibits a small (less than $10 \%$ ) decrease with $R e_{d r y}$. In the liquid stage, a quasisubharmonic frequency $f_{N} \approx f_{0.5}$ is observed, which shows a slight increase (less than 20\%) with $R e_{d r y}$. This is consistent with Fig. 6 and prior studies considering water spraying. ${ }^{18,19}$

The mean cycle-to-cycle amplitudes $\overline{\mathcal{A}}\left(R e_{\text {dry }}\right)$ are presented in Fig. 14(b). The amplitude $\overline{\mathcal{A}}$ increases with $R e_{d r y}$ during both the dry and the liquid stage. Compared to the dry stage, the mean amplitudes are reduced in the liquid stage. Nevertheless, the increase slows down with $R e_{d r y}$ so that it is of interest to further extend the $R e_{d r y}$ range.

The presence of quasi-subharmonic frequency $f_{0.5}$ due to period doubling in the liquid stage indicates that complexity sets in when water is sprayed. ${ }^{19}$ The increased complexity is also apparent considering the increased cycle-to-cycle perturbation measures $\zeta_{T}$ and $\zeta_{\mathcal{A}}$ plotted in Fig. 15. In the dry stage, both perturbation measures yield less than $5 \%$, regardless of $R e_{d r y}$. In the liquid stage, cycleto-cycle irregularities result in a severe increase $(>10 \%)$ of both

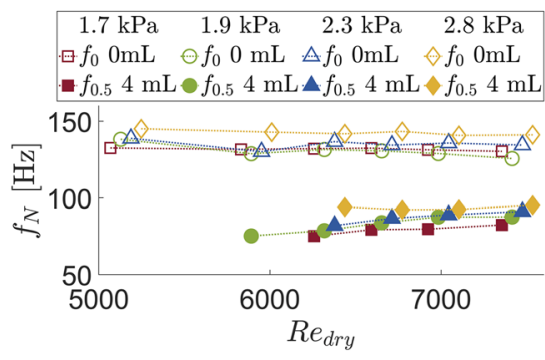

(a)

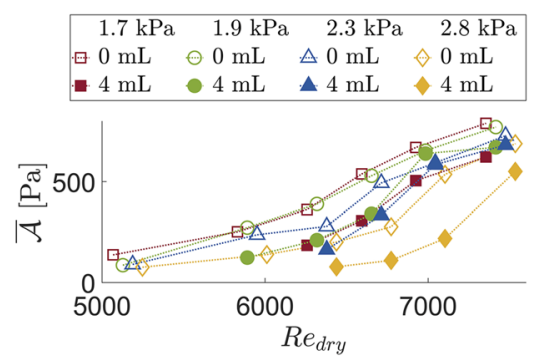

(b)

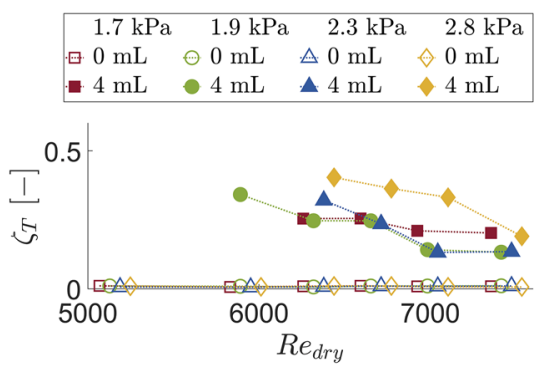

(a)

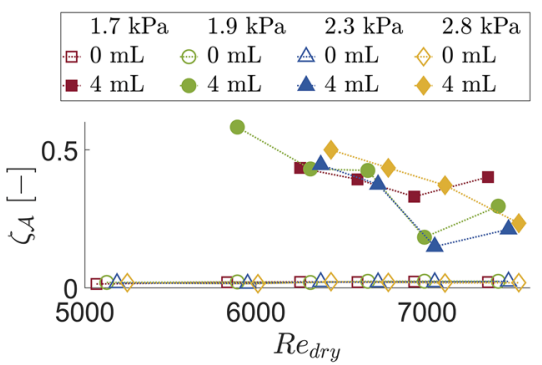

(b)
FIG. 14. Oscillation features for different $P_{P L T}$ (kPa, symbols) in the dry (empty) and liquid (filled) stages for water (LiqO) spraying with $V_{L}=4 \mathrm{ml}$ : (a) frequency $f_{N}\left(R e_{d r y}\right)$ and (b) peak-to-peak cycle amplitude $\overline{\mathcal{A}}\left(\operatorname{Re}_{\mathrm{dry}}\right)$
FIG. 15. Cycle-to-cycle perturbation features for different $P_{P L T}(\mathrm{kPa}$, symbols) in the dry (empty) and liquid (filled) stages for $V_{L}=4 \mathrm{ml}$ water (Liq0) spraying: (a) period $\zeta_{T}\left(R e_{d r y}\right)$ and (b) amplitude $\zeta_{\mathcal{A}}\left(R e_{d r y}\right)$. 


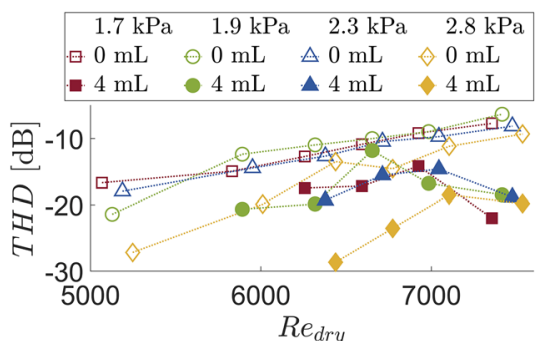

(a)

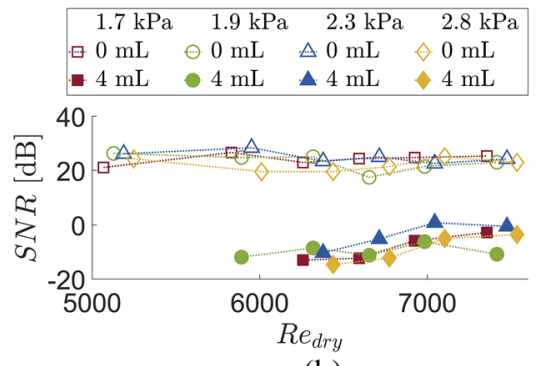

(b)
FIG. 16. Overall spectral features for different $P_{P L T}$ (kPa, symbols) in the dry (empty) and liquid (filled) stages for $V_{L}$ $=4 \mathrm{ml}$ water (Liq0) spraying: (a) total harmonic distortion rate $T H D\left(R e_{d r y}\right)$ and (b) signal-to-noise ratio $S N R\left(R e_{d r y}\right)$. perturbation measures, which decrease with $R e_{d r y}$. Considering again Figs. 13 and 14(b), this implies that the perturbation becomes less important as $\bar{P}_{u}$ and therefore $\overline{\mathcal{A}}$ increases.

The overall spectral measures $T H D\left(R e_{d r y}\right)$ and $S N R\left(R e_{d r y}\right)$ are plotted in Fig. 16. In the dry stage, THD increases with $R e_{d r y}$ (about $10 \mathrm{~dB}$ ) for all elasticity conditions, whereas $\operatorname{SNR}\left(R e_{d r y}\right)$ remains constant at about $25 \mathrm{~dB}$. In the liquid stage, $S N R$ [Fig. 16(b)] is reduced to $20 \mathrm{~dB}$ or more. The decrease is maximum for the lowest $R e_{d r y}$ for which auto-oscillation occurs and becomes less and less with $R e_{d r y}$ thereafter. This is in accordance with the tendencies observed for cycle-to-cycle perturbations $\zeta_{T, \mathcal{A}}$. Therefore, in general, $\zeta_{T, \mathcal{A}}$ and $\operatorname{SNR}\left(R e_{d r y}\right)$ indicate that, in the liquid stage, increasing $R e_{d r y}$ stabilizes the auto-oscillation. From Fig. 16(a), it is seen that the overall
THD increases with $R e_{d r y}$ in both the dry and the liquid stage. Nevertheless, THD in the liquid stage is reduced compared to the dry stage.

\section{Influence of $R_{\text {dry }}$ extended: Water (LiqO) and AS-Artisial (Liq2)}

In this section, the auto-oscillation features for the experiment listed for PLT VF replica montage $I$ in Table VI $\left(V_{L}=3 \mathrm{ml}\right.$ and $\left.P_{P L t}=3.3 \mathrm{kPa}\right)$ are quantified. This way, the impact of viscosity is further assessed using Liq0 and Liq2, while the findings for water spraying in the range $5200 \leq R e_{d r y} \leq 7500$, addressed in Sec. V B 1 for Liq0 (montage $\mathcal{M} I I$ ), are extended to $5200 \leq R e_{d r y} \leq 8300$. This is illustrated in Fig. 17 showing the mean upstream pressure $\bar{P}_{u}\left(R e_{d r y}\right)$
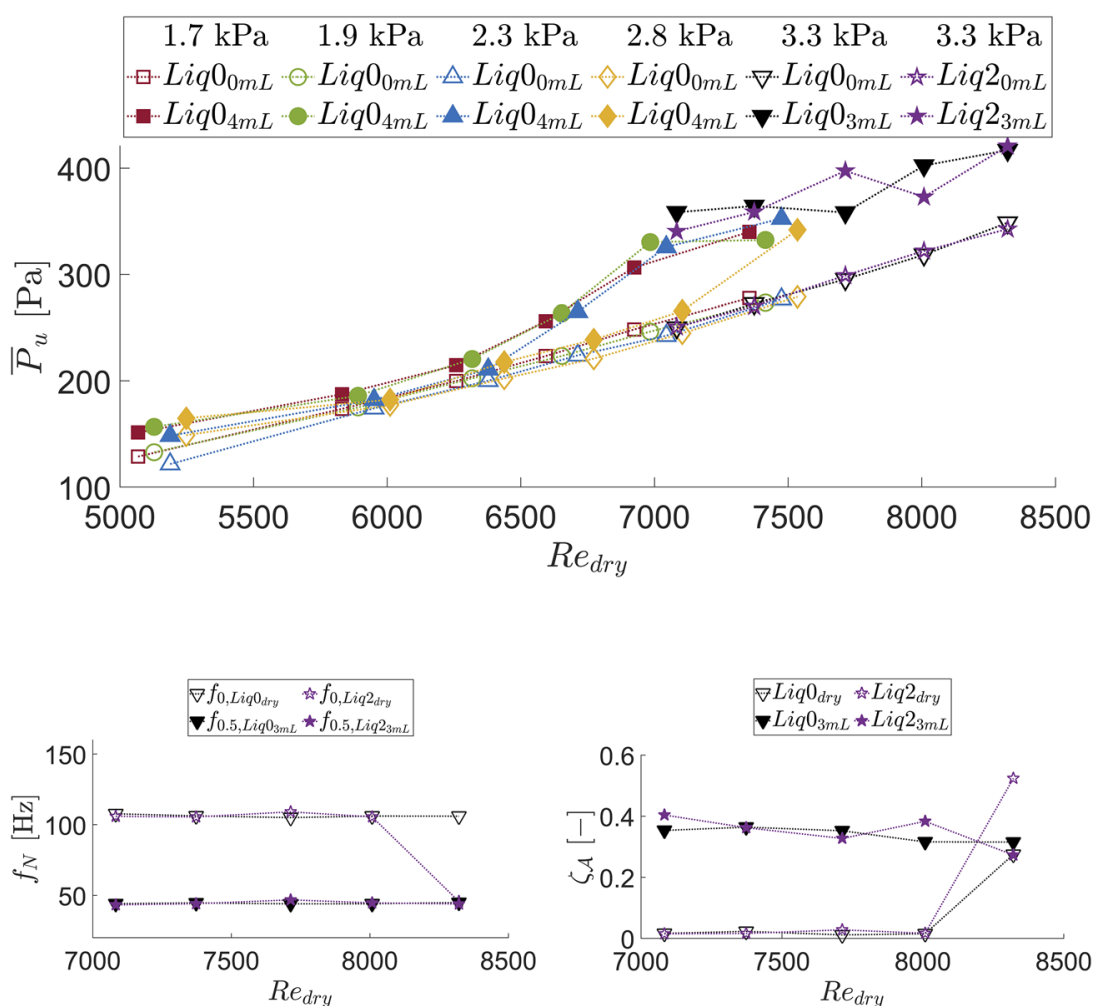

(a)

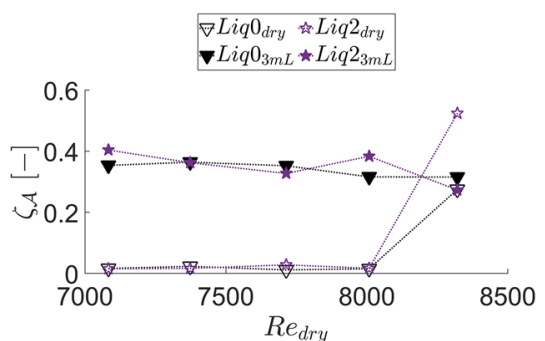

(b)
FIG. 17. Mean upstream pressure $\bar{P}_{u}\left(R e_{d r y}\right)$ for different $P_{P L T} \quad(\mathrm{kPa}$, symbols) in the dry (empty) and in the liquid (filled) stage for water (LiqO) and AS-artisial (Liq2) with $V_{L} \in\{3,4\} \mathrm{ml}$ (subscript).
FIG. 18. Oscillation features for $P_{P I T}$ $=3.3 \mathrm{kPa}$ in the dry (empty) and in the liquid (filled) stage for water (Liq0, $\nabla)$

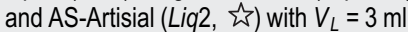
(a) frequency $f_{N}\left(R e_{d r y}\right)$ and (b) cycle-tocycle amplitude perturbation $\zeta_{A}\left(R e_{d r y}\right)$. 
for all flow experiments (montages $\mathcal{M} I$ and $\mathcal{M} I I$ ) listed in Table VI. Overall, $\bar{P}_{u}$-tendencies observed for water $(\operatorname{Liq} 0, \mathcal{M} I I)$ up to $R e_{d r y}$ $\approx 7500$ keep on up to $R e_{d r y} \approx 8300(\mathcal{M} I)$, regardless of the used liquid (Liq0 and Liq2). For each set of experiments (montages $I$ and II), the maximum difference between the dry and the liquid stage remains of similar magnitude $(\approx 100 \mathrm{~Pa})$, regardless of the imposed elasticity condition $P_{P L T}$.

In general, the extracted features for $V_{L}=3 \mathrm{ml}(\mathcal{M} I)$ confirm the findings described in Sec. V B $1\left(V_{L}=4 \mathrm{ml}\right.$, montage $\left.\mathcal{M} I I\right)$. This is illustrated in Fig. 18 for oscillation frequency $f_{N}\left(R e_{d r y}\right)$ and cycleto-cycle amplitude perturbation $\zeta_{A}\left(R e_{d r y}\right)$. The oscillation frequency $f_{N}=f_{0}$ in the dry stage is reduced to $f_{N} \approx f_{0.5}$ in the liquid stage, whereas the cycle-to-cycle perturbation $\zeta_{\mathcal{A}}$ increases from less than $5 \%$ in the dry stage to more than $20 \%$ in the liquid stage. Tendencies with $R e_{d r y}$ observed for other features $\left(\overline{\mathcal{A}}, \zeta_{T}, S N R\right.$, and THD) also confirm the findings described in Sec. V B 1. It is noted that abnormal feature values in the dry stage are retrieved for $R e_{d r y}=8300$, e.g., $f_{N}$ drops and $\zeta_{\mathcal{A}}$ increases (Fig. 18). These abnormalities are due to $f_{0}$ sideband modulation caused by the central tube in the PLT VF replica (Fig. 3). As this is a limitation of the PLT VF replica, larger $R e_{d r y}$ values are not assessed.

\section{DISCUSSION AND CONCLUSION}

Water and two commercially available artificial saliva sprays are sprayed (up to $5 \mathrm{ml}$ ) on an auto-oscillating channel mimicking vocal folds auto-oscillation. The used experimental protocol duplicates hydration with an artificial spray burst so that upstream pressure features without and after hydration are compared. It is seen that the liquid properties affecting air-liquid mixing and surface wettability are similar, except for the dynamic viscosity that is increased when artificial saliva sprays are used (up to 8 times).

In general, increasing the sprayed volume results in the increase in mean upstream pressure, cycle-to-cycle variability, and the decrease in oscillation frequency due period doubling. Therefore, general tendencies of quantified features confirm the previous observations for water spraying, and as such, general tendencies express the loss of determinism. ${ }^{18,19}$ Nevertheless, increasing the dynamic viscosity limits the magnitude of these tendencies for low spraying volumes up to $3 \mathrm{ml}$, providing further evidence that air-liquid mixing determines the flow regime in this case. This implies that hydration with an artificial spray instead of water can reduce the mean upstream pressure and oscillation amplitude, which benefits human voice production and reduces cycle-to-cycle perturbation that improves voice quality.

Liquid viscosity experiments were done at a constant Reynolds number. To consider the influence of upstream airflow supply on the fluid-structure interaction, the Reynolds number characterizing the dry stage is systematically increased from its value at the auto-oscillation onset threshold while the spraying volume is held constant at $3 \mathrm{ml}$ or $4 \mathrm{ml}$. It is observed that, in the liquid stage, the oscillation onset threshold pressure is augmented compared to the dry stage. At the auto-oscillation onset, in the liquid stage, general tendencies associated with liquid spraying hold as cycle-to-cycle perturbation measures, mean upstream pressure, and signal-to-noise ratio increase, whereas the oscillation frequency reduces from $f_{0}$ to $f_{0.5}$. Further increasing the Reynolds number reduces the magnitude of these tendencies for the assessed range of Reynolds numbers. It is verified that the used liquid does not affect these tendencies confirming that for spraying volumes $\geq 3 \mathrm{ml}$, the dynamic viscosity does not affect the observed features. It follows that increasing the airflow supply with respect to the auto-oscillation onset threshold might improve voice quality after hydration at the cost of a larger upstream pressure needed to sustain the auto-oscillation.

The discussed effects are studied for different PLT VF replica elasticity conditions $P_{P L T}$ and montages $\mathcal{M}$. It is shown that the described tendencies remain although their magnitudes can be affected.

\section{ACKNOWLEDGMENTS}

The authors are grateful to Dr. I. Tokuda (Ritsumeikan Univ., Japan) and Tokyo Univ. Hospital for providing the artificial saliva spray AS-Teijin.

\section{DATA AVAILABILITY}

The data that support the findings of this study are available from the corresponding author upon reasonable request.

\section{REFERENCES}

${ }^{1}$ C. Leydon, M. Sivasankar, D. L. Falciglia, C. Atkins, and K. V. Fisher, "Vocal fold surface hydration: A review," J. Voice 23, 658-665 (2009).

${ }^{2}$ J. Gartner-Schmidt, "Voice therapy for the treatment of voice disorders," in Voice Therapy for the Treatment of Voice Disorders, Head \& Neck Surgery - Otolaryngology Vol. 1, 4th ed., edited by B. Bailey, J. Johnson, and S. Newlands (Lippincott Williams \& Wilkins, Philadelphia, USA, 2006), p. 1388.

${ }^{3}$ K. Verdolini, I. R. Titze, and A. Fennell, "Dependence of phonatory effort on hydration level," J. Speech, Lang., Hear. Res. 37, 1001-1007 (1994).

${ }^{4}$ S. Ayache, M. Ouaknine, P. H. Dejonkere, P. Prindere, and A. Giovanni, "Experimental study of the effects of surface mucus viscosity on the glottic cycle," J. Voice 18, 107-115 (2004).

${ }^{5}$ C. Leydon, M. Wroblewski, N. Eichorn, and M. Sivasankar, "A meta-analysis of outcomes of hydration intervention on phonation threshold pressure," J. Voice 24, 637-643 (2010).

${ }^{6}$ M. Dollinger, F. Grohn, D. Berry, U. Eysholdt, and G. Luegmaira, "Preliminary results on the influence of engineered artificial mucus layer on phonation," $J$ Speech, Lang., Hear. Res. 57, S637-S647 (2014).

${ }^{7}$ M. Alves, E. Kruger, B. Pillay, K. van Lierde, and J. van der Linde, "The effect of hydration on voice quality in adults: A systematic review," J. Voice 33, 125.e13125.e28 (2019).

${ }^{8}$ Z.-f. Zou, W. Chen, W. Li, and K. Yuan, "Impact of vocal fold dehydration on vocal function and its treatment," Curr. Med. Sci. 39, 310-316 (2019).

${ }^{9}$ A. Yuan and R. Banerjee, "Comparison of artificial saliva substitutes," Trends Biomater. Artif. Organs 18, 178-186 (2005).

${ }^{10}$ K. Tanner, N. Roy, R. M. Merrill, K. Kendall, K. L. Miller, D. O. Clegg, A. Heller, D. R. Houtz, and M. Elstad, "Comparing nebulized water versus saline after laryngeal desiccation challenge in Sjögren's syndrome," Laryngoscope 123, 2787-2792 (2013).

${ }^{11}$ M. Sivasankar, T. Carroll, A. Kosinski, and C. Rosen, "Quantifying the effects of altering ambient humidity on ionic composition of vocal fold surface fluid," Laryngoscope 123, 1275-1278 (2013).

${ }^{12}$ I. R. Titze, "The physics of small-amplitude oscillation of the vocal folds," J. Acoust. Soc. Am. 83, 1536-1552 (1988).

${ }^{13}$ N. Ruty, X. Pelorson, A. Van Hirtum, I. Lopez-Arteaga, and A. Hirschberg, "An in vitro setup to test the relevance and the accuracy of low-order vocal folds models," J. Acoust. Soc. Am. 121, 479-490 (2007). 
${ }^{14}$ R. Mittal, B. D. Erath, and M. W. Plesniak, "Fluid dynamics of human phonation and speech," Annu. Rev. Fluid Mech. 45, 437-467 (2013).

${ }^{15} \mathrm{~J}$. Weili, Z. Xudong, and X. Qian, "Computational modeling of fluid-structureacoustics interaction during voice production," Front Bioeng. Biotechnol. 5, 7 (2017).

${ }^{16}$ A. Lodermeyer, M. Tautz, S. Becker, M. Dollinger, V. Birk, and S. Kniesburges, "Aeroacoustic analysis of the human phonation process based on a hybrid acoustic PIV approach,” Exp. Fluids 59, 13 (2018).

${ }^{17}$ Z. Li, Y. Chen, S. Chang, and H. Luo, "A reduced-order flow model for fluidstructure interaction simulation of vocal fold vibration," J. Biomech. Eng. 142, 021005 (2019)

${ }^{18}$ A. Bouvet, X. Pelorson, and A. Van Hirtum, "Influence of water spraying on an oscillating channel," J. Fluids Struct. 93, 102840 (2020).

${ }^{19}$ A. Van Hirtum, A. Bouvet, and X. Pelorson, "Quantifying the auto-oscillation complexity following water spraying with interest for phonation," Phys. Rev. E 100, 043111 (2019).

${ }^{20}$ S. K. Lai, Y.-Y. Wang, D. Wirtz, and J. Hanes, "Micro- and macrorheology of mucus," Adv. Drug Delivery Rev. 61, 86-100 (2009).

${ }^{21}$ S. Gittings, N. Turnbull, B. Henry, C. J. Roberts, and P. Gershkovich, "Characterisation of human saliva as a platform for oral dissolution medium development," Eur. J. Pharm. Biopharm. 91, 16-24 (2015).

${ }^{22}$ J. E. Phillips, L. B. Wong, and D. B. Yeates, "Bidirectional transepithelial water transport: Measurement and governing mechanisms," Biophys. J. 76, 869-877 (1999).

${ }^{23}$ K. V. Fisher, J. Ligon, J. L. Sobecks, and D. M. Roxe, "Phonatory effects of body fluid removal," J. Speech, Lang., Hear. Res. 44, 354-367 (2001).

${ }^{24} \mathrm{M}$. Sivasankar and K. V. Fisher, "Vocal fold epithelial response to luminal osmotic perturbation,” J. Speech, Lang., Hear. Res. 50, 886-898 (2007).

${ }^{25}$ A. Van Hirtum, A. Bouvet, and X. Pelorson, "Pressure drop for adiabatic airwater flow through a time-varying constriction," Phys. Fluids 30, 101901 (2018).
${ }^{26}$ A. Bouvet, "Experimental and theoretical contribution to the analysis and the modelling of the vocal folds vibration," Ph.D. thesis, Grenoble Alpes University, France, 2019.

${ }^{27}$ B. Scharfman, A. Techet, J. Bush, and L. Bourouiba, "Visualization of sneeze ejecta: Steps of fluid fragmentation leading to respiratory droplets," Exp. Fluids 57, 24 (2016).

${ }^{28}$ T. Dbouk and D. Drikakis, "On coughing and airborne droplet transmission to humans," Phys. Fluids 32, 053310 (2020).

${ }^{29}$ J. D. Berry, M. J. Neeson, R. R. Dagastine, D. Y. C. Chan, and R. F. Tabor, "Measurement of surface and interfacial tension using pendant drop tensiometry," J. Colloid Interface Sci. 454, 226-237 (2015).

${ }^{30}$ P. G. de Gennes, "Wetting: Statics and dynamics," Rev. Mod. Phys. 57, 827-863 (1985).

${ }^{31}$ W. Abdallah, J. Buckley, A. Carnegie, J. Edwards, B. Herod, E. Fordham, A. Graue, T. Habashy, N. Seleznev, C. Signer, H. Hussain, B. Montaron, and M. Ziauddin, "Fundamentals of wettability," Oilfield Rev. 19, 44-61 (2007).

${ }^{32}$ A. Van Hirtum and X. Pelorson, "High-speed imaging to study an autooscillating vocal fold replica for different initial conditions," Int. J. Appl. Mech. 9, 1750064 (2017).

${ }^{33}$ J. Cisonni, A. Van Hirtum, X. Pelorson, and J. Willems, "Theoretical simulation and experimental validation of inverse quasi-one-dimensional steady and unsteady glottal flow models," J. Acoust. Soc. Am. 124, 535-545 (2008).

${ }^{34}$ R. L. Plant, G. L. Freed, and R. E. Plant, "Direct measurement of onset and offset phonation threshold pressure in normal subjects," J. Acoust. Soc. Am. 116, 36403646 (2004).

${ }^{35}$ M. Hirano and K. R. McCormick, in Clinical Examination of Voice (Acoustical Society of America, 1986), Vol. 80, pp. 1273.

${ }^{36} \mathrm{M}$. Hirano, S. Kurita, and T. Nakashima, "Growth, Development and Aging of Human Vocal Folds," in Vocal Fold Physiology: Contempory Research and Clinical Issues (College-Hill Press, 1983), pp. 22-43. 